\title{
Effect of preoperative hospitalization period on post-operative cognitive dysfunction in patients undergoing hip surgery under regional anesthesia
}

\author{
Burcu OZALP HORSANALI ${ }^{1}$, Murat OZKALKANLI ${ }^{2}$, Zeki TEKGUL ${ }^{3}$, and Fulya \\ YILMAZ $^{3}$ \\ ${ }^{1}$ Ege University Faculty of Medicine \\ ${ }^{2}$ Izmir Katip Celebi University Ataturk Training and Research hospital \\ ${ }^{3}$ Izmir Bozyaka Training and Research Hospital
}

November 20, 2020

\begin{abstract}
Objective: The main objective of this prospective and observational study is to investigate the effect of preoperative hospitalization period on early postoperative cognitive dysfunction (POCD) development in patients undergoing total hip replacement surgery under regional anesthesia. Materials and Methods: Between November 2013 to September 2014, 64 patients were enrolled the study. Test scores were obtained on the initial admission day (MMT1), 24 hours prior to surgery (MMT2) and 24 hours after the surgery (MMT3). Patients were divided into two groups according to MMT scores as "no cognitive dysfunction" (Group 1) and "cognitive dysfunction" (Group 2). Differences between groups were evaluated statistically. Statistical significance level was set as $\mathrm{p}<0.05$ in a $95 \%$ confidential interval. Results: POCD incidence rate was calculated as $43.8 \%$ in all patients. Preoperative hospitalization duration was significantly higher in patients with POCD when compared to patients without POCD $(\mathrm{p}<0,001)$. The factors which affect POCD development were found to be advanced age ( $<0,001)$, high ASA scores $(p=0,004)$, presence of comorbid disease $(p=0,025)$, duration of operation $(p=0,018)$ and decreased postoperative hematocrit levels $(\mathrm{p}=0,014)$. Conclusion: In this study, we observed patients with early POCD had a relatively longer pre-operative hospitalization period when compared to patients without POCD. We consider that the prolonged preoperative hospitalization periods may contribute to increased POCD incidence rates in patients with risk factors.
\end{abstract}

Effect of preoperative hospitalization period on post-operative cognitive dysfunction in patients undergoing hip surgery under regional anesthesia

\section{ABSTRACT}

Aim of the study: The main objective of this prospective and observational study is to investigate the effect of preoperative hospitalization period on early postoperative cognitive dysfunction (POCD) development in patients undergoing total hip replacement surgery under regional anesthesia.

Materials and Methods: Between November 2013 to September 2014, 64 patients were enrolled the study. Test scores were obtained on the initial admission day (MMT1), 24 hours prior to surgery (MMT2) and 24 hours after the surgery (MMT3). Patients were divided into two groups according to MMT scores as "no cognitive dysfunction" (Group 1) and "cognitive dysfunction" (Group 2). Differences between groups were evaluated statistically. Statistical significance level was set as $\mathrm{p}<0.05$ in a $95 \%$ confidential interval.

Results: POCD incidence rate was calculated as $43.8 \%$ in all patients. Preoperative hospitalization duration was significantly higher in patients with POCD when compared to patients without POCD $(\mathrm{p}<0,001)$. 
The factors which affect POCD development were found to be advanced age $(\mathrm{p}<0,001)$, high ASA scores $(\mathrm{p}=0,004)$, presence of comorbid disease $(\mathrm{p}=0,025)$, duration of operation $(\mathrm{p}=0,018)$ and decreased postoperative hematocrit levels $(\mathrm{p}=0,014)$.

Conclusion: In this study, we observed patients with early POCD had a relatively longer pre-operative hospitalization period when compared to patients without POCD. We consider that the prolonged preoperative hospitalization periods may contribute to increased POCD incidence rates in patients with risk factors.

\section{What is known?}

- Hip surgery is one of the most common surgical procedure in daily orthopedic operations

- Development of cognitive dysfunction after hip surgery is common. This is one of the most important problem that cause prolonged hospitalization period after surgery

- The most common risk factors of cognitive dysfunction after hip surgery includes advanced age, presence of comorbidities, scale of operation and post-operative pain

\section{What is new?}

- Although known risk factors of cognitive dysfunction are related with postoperative period and presence of comorbidities, there is no study investigating the effect of prolonged preoperative hospitalization period on cognitive dysfunction

- This study revealed that prolonged preoperative hospitalization period is an independent risk factor regardless of the other risk factors for cognitive dysfunction after hip surgery

- Reducing preoperative hospitalization period significantly decrease postoperative cognitive dysfunction development

Keywords: Cognitive dysfunction, Hip Surgery, Mini mental Test, Preoperative Hospitalization, Epidural Anesthesia

\section{Introduction}

Post-operative cognitive dysfunction (POCD) is defined as a decrease in cognitive functions which develop following surgery and anesthesia administration that may continue weeks or even months after surgery (1).

POCD clinical signs include psychomotor imbalance, memory loss, dementia, difficulties in fine-motor skills and upper level cognitive dysfunctions (2). Sensitive tests reported that this decline in psychomotor and cognitive functions in those patients following surgery may last from a week to three months and even in some rare cases, up to 1-2 years (3).

Previous studies on non-cardiac surgery patients over 18-age reported POCD incidence rate is between $19-41 \%$ (2). This rate may increase to $80 \%$ following cardiac surgery (4). In elderly hip replacement surgery patients, this rate is reported to be between $15-60 \%$ (5). The most common risk factors for POCD development were reported as advanced age, presence of comorbidities, scale of operation and post-operative pain (6). However, there are no studies in the literature that revealed the effect of prolonged preoperative hospitalization duration on POCD development.

In this study, we aimed to investigate the effect of preoperative hospitalization period on early POCD development and its risk factors in patients undergoing total hip replacement surgery for hip fractures under regional anesthesia.

\section{Materials and Methods}

This prospective and observational study was initiated after obtaining the approval for the study from Izmir Bozyaka Training and Research Hospital Ethics Committee on 27/03/2013 with decision number 17/7. The study evaluated Mini Mental Test (MMT) scores of patients who received total hip replacement surgery in Izmir Bozyaka Training and Research Hospital from November 2013 to September 2014. In the assessment, Mini Mental Test (MMT) was used for literate and Modified Mini Mental Test (MMMT) was used for illiterate patients (7). Test scores were obtained on the initial admission day (MMT1), 24 hours prior to 
surgery (MMT2) and 24 hours after the surgery (MMT3). A drop of 4 points or more between each test was defined as significant cognitive dysfunction development. Patients who did not have any change or a change less than 4 points between MMT1 and MMT3 were grouped as "no cognitive dysfunction" (Group 1) and patients with a difference more than 4 points between MMT1 and MMT3 were grouped as "cognitive dysfunction" (Group 2). All analyses were performed using those 2 patient groups.

Patients who were planned to undergo total hip replacement surgery without cement over 18 years of age and within ASA Group 1, 2 and 3 according to ASA physical status score were included in the study.

Patients younger than 18, who did not speak Turkish, precense the history of cancer diagnosis, previous steroid treatment, serebro vascular disease history in last 6 months, central nervous system diseases (current meningitis, encephalitis, tumors, major degenerative diseases), dementia, Alzheimer's and Parkinson's Disease, neuropsychiatric diseases or received antidepressant, antipsychotic or anticonvulsive treatment in the last 6 months, uncooperative patients, substance abuse, severe organ failure (end-stage liver failure, dialysis-dependent kidney failure), requiring ICU following surgery, patients where regional anesthesia was contraindicated (Idiopathic intracranial hypertension (IIH), clotting disorders, infection on operational site) and pregnant patients were excluded from the study.

No premedication was performed on patients during preoperative period. Hydration during preoperative period was performed by IV $0.9 \% \mathrm{NaCl}$ aqueous solution with a fasting period of 6-10 hours prior to surgery.

In our study, combined spinal-epidural anesthesia was used for anesthesia for all the patients. Surgical intervention was allowed on the patients with sensory block on T8 dermatome levels. Patients also received gradually $0.5 \mathrm{mg}$ IV bolus midazolam until to be Ramsey Sedation Scale 3 .

During anesthesia, decreasing systolic blood pressure more than $20 \%$ compared to preoperative period was defined as hypotension. $5 \mathrm{mg}$ IV Ephedrine was administered to the patients when their mean arterial blood pressure levels decreased $50 \mathrm{mmHg}$ or below despite fluid replacement. Bradycardia was defined as pulses below $40 \mathrm{bpm}$ and was treated with $0.5 \mathrm{mg}$ IV atropine.

Postoperative pain management was planned according to Visual Analogue Scale (VAS). In patients with VAS score 3 and above, $10 \mathrm{ml}$ isobaric bupivacaine $0.125 \%$ was administered through epidural catheter. No additional medication (opiates or NSAIDs) were used for analgesia.

Demographics, education levels, employment status, operation indications, ASA scores, comorbid diseases and tobacco use of all patients were questioned and recorded. Scores of MMT or MMMT of patients on their initial admission, 24 hours prior to surgery and 24 hours after surgery and its parameters were all recorded and classified.

The period from hospitalization to the surgery date was calculated and recorded. Patients' hemoglobin, hematocrit, serum electrolyte levels on initial admission, preoperative and postoperative periods, anesthesia duration, surgery duration, administered midazolam, atropine and ephedrine doses, crystalloid, colloid, blood and blood products used during surgery and total blood loss volume were all recorded.

\section{Statistical Analysis}

All statistical analysis was performed using SPSS v.17.0 software (SPSS Inc, Chicago, IL). Shapiro-Wilk test was used to check distribution of numerical values. Categorical variables were expressed with frequency and percentage values whereas numerical values were expressed as mean, standard deviation or median and min-max values. Chi-square test was used to analyze the relationship between two categorical variables. Nonparametric Friedman test was used to compare 2 or more consecutive MMT score mean values and Wilcoxon signed series test was used to compare two dependent score mean values. Independent sample mean values were compared using non-parametric Mann-Whitney U test. The difference between independent median measurements were assessed using non-parametric median test. Pearson Correlation Test was used to analyze the relationship between numerical values. All analyses were performed on a $95 \%$ confidence interval and $\mathrm{p}<0.05$ values were deemed as statistically significant. 


\section{Results}

Sixty-four patients were enrolled the study. There were 27(42\%) male and $37(58 \%)$ female patients. Mean preoperative hospitalization period of all patients were $6.6 \pm 4.3$ days. $26(40.6 \%)$ patients did not have any comorbidities whereas $14(21.9 \%)$ of had one and $24(37.5 \%)$ of had multiple chronic diseases.

Although preoperative blood glucose levels were above $200 \mathrm{mg} / \mathrm{dL}$ for 9 (14.1\%) of patients and serum creatinine levels were above $2 \mathrm{mg} / \mathrm{dl}$ for $7(10.9 \%)$ of patients, Other laboratory results were within normal limits.

Mean admission MMT scores were $26.42 \pm 1.95,25.48 \pm 3.02$ and $23.95 \pm 3.68$ point for MMT1, MMT2 and MMT3, respectively. A statistically significance was observed in consecutive total MMT score measurements $(\mathrm{p}<0.001)$. We observed mean MMT1 total score was significantly higher than mean MMT2 and MMT3 total scores whereas mean MMT2 total score was higher than mean MMT3 total scores.

Mean MMT1 total score was calculated as $26.67 \pm 2.17$ for Group 1 and $26.11 \pm 1.62$ for Group 2. There was no statistical significance was found according to mean MMT1 total scores between 2 groups $(\mathrm{p}=0.350)$. Table 1 summarizes the association between POCD and demographic values between groups. There were statistically significance between POCD development and age, education level, employment status whereas no difference was found between POCD development and gender.

Table 2 summarized the differences between clinicopathological characteristics, perioperative factors and groups. Statistical significance was observed between groups in terms of preoperative hospitalization period $(\mathrm{p}<0.001)$ and it was significantly longer in POCD patients. According to our results, the presence of comorbidity causes the development of POCD and prolonging preoperative hospitalization period that attribute the development of POCD ( $\mathrm{p}=0.025)$. High ASA score, prolonged surgery time, preoperative low hematocrite level $(<30)$, ephedrine administration ve increased hemorrhage during surgery were associated POCD development (table -2). Table-3 summarized the association between ASA scores and POCD development. According to table-3, we statistically found significance between more POCD development and increased ASA scores.

When comorbidities were separately analysed, a significant association was observed between POCD development with hypertension and coronary artery disease $(\mathrm{p}=0.036),(\mathrm{p}=0.015)$. There were no statistical significance between POCD development and diabetes mellitus (DM) $(\mathrm{p}=0.353)$, chronic obstructive pulmoner disease $(\mathrm{COPD})(\mathrm{p}=0.353)$, congestive heart failure $(\mathrm{CHF})(\mathrm{p}=0.259)$. Also, there were no statistical significance between prolonged preoperative hospitalization periods with hypertension, coronary artery diseases, DM, COPD and CHF, respectively $(\mathrm{p}=0,2),(\mathrm{p}=0,076),(\mathrm{p}=0,153),(\mathrm{p}=0,307),(\mathrm{p}=0,324)$. And also, there were no statistical significance between POCD development with tobacco use, glucose and creatinine levels (p: 0,863), (p:0,488), (p: 0,488).

\section{Discussions}

In this study, we investigated the effect of preoperative hospitalization periods on early POCD development and the associated risk factors in adult patients undergoing total hip placement surgery under regional anesthesia. We observed a higher POCD incidence rate in patients with prolonged preoperative hospitalization period, advanced age, high ASA score, present comorbidities, extended operation periods and low post-op hematocrit levels.

Mean MMT scores of the patients were significantly lower when compared MMT scores at 24 hours after the operation and initial admission MMT scores, which demonstrated us cognitive dysfunction. In our study, at 24-hour POCD after surgery incidence rate was $43.8 \%$. Our results were similar with the previous studies.

In previous studies reported orthopedic surgeries on elderly patients had a high risk of developing POCD and incidence was reported as 15-60\% among especially elderly patients after hip fracture surgery $(5,8)$.

Advanced age is reported the most important risk factor for developing POCD (9). Elderly patients were reported to have a higher risk of developing POCD compared to younger patients $(10,11)$. In the study 
of Salazar including 150 patients reported that POCD incidence rate in patients over 65 was $12 \%$ at $4^{\text {th }}$ day after knee replacement surgery (12). In ISPOCD1 study including 1218 patients over 60 who underwent non-cardiac surgery reported POCD incidence rate was $25.8 \%$ (13).

We revealed statistical significance between age and POCD development. Mean age of the patients who did not develop POCD in 24 hours was $50.6 \pm 21.9$ years, while patients who developed POCD, the mean age was $79.0 \pm 10.0$ years.

The previous studies in the literature also report the ASA risk classification may play an important role on cognitive functions. A study which included 118 patients over 75 who underwent major abdominal surgery reported postoperative delirium in 28 (24\%) of the patients and ASA 3 score is one of the risk factors for the development of POCD (14). In our study, Although 46.4\% of patients who developed POCD had ASA 1-2 score, $53.6 \%$ of had ASA 3 score. Our results are similar with the previous studies which reported a significant association between POCD development and high ASA scores.

Presence of comorbidity, which is one of the most important factors in the assessment of ASA scores, is also reported to be a risk factor in POCD development in various studies (15). In addition, several studies reported association between not only with diabetes and hypertension, but also with coronary artery disease (CAD), congestive heart failure (CHF), respiratory diseases and POCD development (16). In this study, we also found a significant association between presence of comorbidities and POCD development. When comorbidities were classified and evaluated separately, HT and CAD were found to be a risk factor for POCD development. We consider that association between presence of comorbidities and POCD development may be depend on the level of systemic effects of the comorbid disease and duration.

The effect of prolonged preoperative hospitalization period on POCD development was evaluated in this study regardless of the factors such comorbidities and high ASA scores, which might affect the preoperative hospitalization period. Our results showed us that the preoperative hospitalization period is significantly longer in patients who developed POCD compared to other patients, regardless of comorbidity presence and high ASA score factors. Patients without POCD had a lower mean preoperative hospitalization period compared to patients who developed POCD.

There are limited studies in the literature investigating the effect of preoperative hospitalization period on POCD development. In a study including 54 patients reported that even an increase in hospitalization periods from 14 hours to 32 hours could be attributed to delirium development in postoperative period (17). Although POCD and delirium could be clinically similar, they are different diagnoses that should be differentiated properly. Another study performed on elderly patients operated for hip fractures also reported that increased preoperative hospitalization periods could also increase postoperative hospitalization and might cause POCD development in those cases (5).

Most of the important risk factors for POCD development are patient-related and could not be changed. Especially elderly patients with comorbidities and high ASA scores are under a high risk for POCD development. Moreover, POCD could be seen even in postoperative $3^{\text {rd }}$ month in $14 \%$ of those patients (18). Since prolonged preoperative hospitalization periods could affect POCD development after surgery, regardless of other factors, we suggest preoperative hospitalization period should be minimized in patients have risk factors for developing POCD.

In the study of Bitsch including 100 operated hip fracture patients reported a severe cognitive dysfunction in $32 \%$ of patients. According to this study, age is a risk factor for POCD, in addition to low postoperative hematocrit (Htc) and perioperative transfusion volume (5). According to our study results, postoperative Htc levels had a significant effect on postoperative MMT values similar to Bitsch' study.

Although blood loss volume and postoperative Htc values might be related with POCD, in our study, we could not observed a significant association between POCD development and total transfused erythrocyte suspension volume, crystalloid and colloid replacement. Erythrocyte and liquid transfusion must be planned according to preoperative Htc values of the patient and his comorbidities which may be related and cause 
different outcomes among patients with POCD.

In our study, we found a significant association between POCD development and ephedrine administration. Although there are no studies investigating association between ephedrine administration and POCD in such surgeries, we consider that this is probably due to ephedrine-induced hypotension, not ephedrine administration.

There are some studies reported increased POCD incidence rates with prolonged surgery periods (19). In our study, we also observed that the POCD group had a longer operation time compared to the non-POCD group, in accordance with the literature.

Some of the limitations of this study are its low patient population and short-term evaluation of postoperative cognitive functions. Longer follow-up periods in patients with cognitive function assessment will be beneficial for long-term results.

\section{Conclusions}

We revealed POCD patients had a significantly longer preoperative hospitalization period when compared to non-POCD patient group. In addition, POCD development was associated with advanced age, presence of comorbidity, high ASA scores, prolonged surgery duration, increased intraoperative blood loss amount and low postoperative hematocrit levels. We consider prolonged preoperative hospitalization periods were related with early POCD development and patients had risk factors should be closely monitorised post operatively in terms of cognitive functions.

\section{Acknowledgements}

Not applicable

\section{Disclosure}

The authors have no conflicts of interest to declare in regards to the materials discussed in this article.

\section{References}

1. Rasmussen LS. Postoperative cognitive dysfunction: incidence and prevention. Best practice \& research Clinical anaesthesiology. 2006;20(2):315-30.

2. Coburn M, Fahlenkamp A, Zoremba N, Schaelte G. Postoperative kognitive Dysfunktion. Der Anaesthesist. 2010;59(2):177-85.

3. Tsai TL, Sands LP, Leung JM. An update on postoperative cognitive dysfunction. Advances in anesthesia. 2010;28(1):269-84.

4. Arrowsmith J, Grocott H, Reves J, Newman M. Central nervous system complications of cardiac surgery. British journal of anaesthesia. 2000;84(3):378-93.

5. Bitsch M, Foss NB, Kristensen BB, Kehlet H. Acute cognitive dysfunction after hip fracture: frequency and risk factors in an optimized, multimodal, rehabilitation program. Acta anaesthesiologica scandinavica. 2006;50(4):428-36.

6. Edlund A, Lundström M, Lundström G, Hedqvist B, Gustafson Y. Clinical profile of delirium in patients treated for femoral neck fractures. Dementia and geriatric cognitive disorders. 1999;10(5):325-9.

7. Güngen C, Ertan T, Eker E, Yaşar R, Engin F. Standardize mini mental test'in Türk toplumunda hafif demans tan> S> nda gecerlik ve guvenilirliği. Türk Psikiyatri Dergisi. 2002;13(4):273-81.

8. Abildstrom H, Rasmussen L, Rentowl P, Hanning C, Rasmussen H, Kristensen P, et al. Cognitive dysfunction 1-2 years after non-cardiac surgery in the elderly. Acta Anaesthesiologica Scandinavica. 2000;44(10):124651. 
9. Wang Y, Sands LP, Vaurio L, Mullen EA, Leung JM. The effects of postoperative pain and its management on postoperative cognitive dysfunction. The American journal of geriatric psychiatry. 2007;15(1):50-9.

10. Kotekar N, Kuruvilla CS, Murthy V. Post-operative cognitive dysfunction in the elderly: A prospective clinical study. Indian journal of anaesthesia. 2014;58(3):263.

11. Brown EN, Purdon PL. The aging brain and anesthesia. Current Opinion in Anesthesiology. 2013;26(4):414-9.

12. Salazar F, Donate M, Boget T, Bogdanovich A, Basora M, Torres F, et al. Intraoperative warming and post-operative cognitive dysfunction after total knee replacement. Acta anaesthesiologica scandinavica. 2011;55(2):216-22.

13. Moller J, Cluitmans P, Rasmussen L, Houx P, Rasmussen H, Canet J, et al. Long-term postoperative cognitive dysfunction in the elderly: ISPOCD1 study. The Lancet. 1998;351(9106):857-61.

14. Brouquet A, Cudennec T, Benoist S, Moulias S, Beauchet A, Penna C, et al. Impaired mobility, ASA status and administration of tramadol are risk factors for postoperative delirium in patients aged 75 years or more after major abdominal surgery. Annals of surgery. 2010;251(4):759-65.

15. Wu CL, Hsu W, Richman JM, Raja SN. Postoperative cognitive function as an outcome of regional anesthesia and analgesia. Regional Anesthesia \& Pain Medicine. 2004;29(3):257-68.

16. Wang W, Wang Y, Wu H, Lei L, Xu S, Shen X, et al. Postoperative cognitive dysfunction: current developments in mechanism and prevention. Medical Science Monitor: international medical journal of experimental and clinical research. 2014;20:1908.

17. Laalou F, Carre A, Forestier C, Sellal F, Langeron O, Pain L. Pathophysiology of post-operative cognitive dysfunction: current hypotheses. Journal de chirurgie. 2008;145(4):323-30.

18. Gao L, Taha R, Gauvin D, Othmen LB, Wang Y, Blaise G. Postoperative cognitive dysfunction after cardiac surgery. Chest. 2005;128(5):3664-70.

19. Plaschke K, Hauth S, Jansen C, Bruckner T, Schramm C, Karck M, et al. The influence of preoperative serum anticholinergic activity and other risk factors for the development of postoperative cognitive dysfunction after cardiac surgery. The Journal of thoracic and cardiovascular surgery. 2013;145(3):805-11.

Table and Figure legends

Table 1 - Comparison of MMT1-MMT3 and demographics of the study groups

\begin{tabular}{lllll}
\hline & & Group 1 & Group 2 & P value \\
\hline Age, years & & $50,6 \pm 21,9$ & $79,0 \pm 10,0$ & $<\mathbf{0 , 0 0 1}$ \\
Gender & Male Female & $19(52,8 \%) 17$ & $8(28,6 \%) 20$ & 0,052 \\
& & $(47,2 \%)$ & $(71,4 \%)$ & \\
Education & No Yes & $8(22,2 \%) 28$ & $15(53,6 \%) 13$ & $\mathbf{0 , 0 1}$ \\
Employed & \multirow{2}{*}{ No Yes } & $(77,8 \%)$ & $(46,3 \%)$ & \\
& & $20(55,6 \%) 16$ & $26(92,9 \%) 2(7,1 \%)$ & $\mathbf{0 , 0 0 1}$ \\
\hline
\end{tabular}

Table-2 The relationship between ASA score and present comorbidities with POCD

\begin{tabular}{llll}
\hline & Group 1 & Group 2 & p Value \\
\hline ASA 1-2 & $29(80.6 \%)$ & $13(46.4 \%)$ & $\mathbf{0 . 0 0 4}$ \\
ASA 3 & $7(19.4 \%)$ & $15(53.6 \%)$ &
\end{tabular}




\begin{tabular}{|c|c|c|c|}
\hline & Group 1 & Group 2 & p Value \\
\hline $\begin{array}{l}\text { Comorbidity Present } \\
\text { Absent }\end{array}$ & $17(47.2 \%) 17 / 47.2 \%)$ & $7(25 \%) 21(75 \%)$ & 0.025 \\
\hline $\begin{array}{l}\text { Preoperative } \\
\text { Hospitalization } \\
\text { period, day } \\
\text { Comorbidity present } \\
\text { Comorbidity absent }\end{array}$ & $3.9 \pm 2.66 .1 \pm 4.0$ & $5.9 \pm 2.59 .8 \pm 4.2$ & 0.0470 .008 \\
\hline $\begin{array}{l}\text { Surgery Duration } \\
(\min )(\text { mean } \pm S D)\end{array}$ & $125.4 \pm 29.5$ & $148.9 \pm 39.9$ & 0.018 \\
\hline $\begin{array}{l}\text { Hematocrit }(n, \%)<30 \\
>30\end{array}$ & $16(44,4 \%) 20(55,6 \%)$ & $21(75 \%) 7(25 \%)$ & 0.014 \\
\hline $\begin{array}{l}\text { Atropine }(n, \%) \\
\text { Administered Not } \\
\text { administered }\end{array}$ & $34(94.4 \%) 2(5.6 \%)$ & $26(92.9 \%) 2(7.1 \%)$ & $>0.999$ \\
\hline $\begin{array}{l}\text { Ephedrine }(n, \%) \\
\text { Administered Not } \\
\text { administered }\end{array}$ & $33(91.7 \%) 3(8.3 \%)$ & $15(53.6 \%) 13(46.4 \%)$ & $<0.001$ \\
\hline $\begin{array}{l}\text { Midazolam }(n, \%) \\
\text { Administered Not } \\
\text { administered }\end{array}$ & $19(52.8 \%) 17(47.2 \%)$ & $19(67.9 \%) 9(32.1 \%)$ & 0.223 \\
\hline $\begin{array}{l}\text { Crystalloid }(\mathbf{m l}) \\
(\text { Mean } \pm S D)\end{array}$ & $2222 \pm 806$ & $1821 \pm 495$ & 0.087 \\
\hline $\begin{array}{l}\text { Colloid Replacement } \\
\text { (n, \%) Administered Not } \\
\text { administered }\end{array}$ & $21(58.3 \%) 15(41.7 \%)$ & $18(64.3 \%) 10(35.7 \%)$ & 0.628 \\
\hline $\begin{array}{l}\text { Hemorrhage }(\mathbf{m l}) \\
(\text { Mean } \pm S D)\end{array}$ & $633.3 \pm 305.9$ & $764.3 \pm 322.3$ & 0.046 \\
\hline $\begin{array}{l}\text { Erythrocyte } \\
\text { Replacement ( } n, \%) \\
\text { Administered Not } \\
\text { administered }\end{array}$ & $21(58.3 \%) 15(41.7 \%)$ & $19(67.9 \%) 9(32.1 \%)$ & 0.892 \\
\hline
\end{tabular}

Table-3 The relationship between preoperative hospitalization period and POCD development according to ASA scores

\begin{tabular}{llll}
\hline & $\begin{array}{l}\text { Preoperative } \\
\text { Hospitalization } \\
\text { Period (day) }\end{array}$ & $\begin{array}{l}\text { Preoperative } \\
\text { Hospitalization } \\
\text { Period (day) }\end{array}$ & p Value \\
\hline ASA-1 & Group 1 & Group 2 & \\
ASA-2 & $3,9 \pm 3,2(\mathrm{n}=11)$ & $5,0(\mathrm{n}=1)$ & $\mathrm{N}$ \\
ASA-3 & $5,4 \pm 3,9(\mathrm{n}=18)$ & $8,3 \pm 4,2(\mathrm{n}=12)$ & 0,041 \\
\hline
\end{tabular}

\section{Hosted file}

Table 1.pdf available at https://authorea.com/users/377459/articles/494127-effect-ofpreoperative-hospitalization-period-on-post-operative-cognitive-dysfunction-in-patientsundergoing-hip-surgery-under-regional-anesthesia 


\section{Hosted file}

Table-2.pdf available at https://authorea.com/users/377459/articles/494127-effect-ofpreoperative-hospitalization-period-on-post-operative-cognitive-dysfunction-in-patientsundergoing-hip-surgery-under-regional-anesthesia

\section{Hosted file}

Table-3.pdf available at https://authorea.com/users/377459/articles/494127-effect-ofpreoperative-hospitalization-period-on-post-operative-cognitive-dysfunction-in-patientsundergoing-hip-surgery-under-regional-anesthesia 